\title{
Comparative evaluation of different immunoassays for the detection of Taenia solium cysticercosis in swine with low parasite burden
}

\author{
Andréia Bartachini Gomes, Killarney Ataíde Soares*, Ednéia Casagrande Bueno**, \\ Noeli Maria Espindola, Alberto Hiroshi Iha, Antônio Augusto Mendes Maia*, \\ Regina Helena Saramargo Peralta***, Adelaide José Vaz ${ }^{+}$
}

\begin{abstract}
Departamento de Análises Clínicas, Faculdade de Ciências Farmacêuticas, Universidade de São Paulo, Av. Prof. Lineu Prestes 580, bloco 17, 05508-900 São Paulo, SP, Brasil *Departamento de Ciências Básicas, Faculdade de Zootecnia e Engenharia de Alimentos, Universidade de São Paulo, Pirassununga, SP, Brasil **Núcleo de Investigações Químico-Farmacêuticas, Universidade do Vale do Itajaí, Itajaí, SC, Brasil ***Departamento de Patologia, Faculdade de Medicina, Universidade Federal Fluminense, Hospital Universitário Antonio Pedro, Niterói, RJ, Brasil
\end{abstract}

Seven swine were experimentally infected with Taenia solium eggs and blood samples from each animal were periodically collected. At the end of the experiment (t140) the animals did not show clinical aspects of cysticercosis or parasites in tongue inspection. All animals were slaughtered and cut into thin slices in searching for cysts. The number of cysts found in each animal varied from 1 to 85. Enzyme-linked immunosorbent assay (ELISA) tests for antibody $(\mathrm{Ab})$ detection and for antigen $(\mathrm{Ag})$ detection were performed, which presented respectively 71 and $57 \%$ of positivity.

By immunoblot (IB), using 18/14 (T. crassiceps $A g$ ) or lentil-lectin-purified glycoproteins from T. solium $A g$ (LLGP) as Ag, five (71\%) and six (86\%) animals were positive, respectively. The association between Ag-ELISA with any IB (18/14 or LLGP) allowed the detection of all animals at 140 days post-experimental infection (days p.e.i.). The use of IB 18/14 combined to the Ag-ELISA allowed the detection of all animals since 70 days p.e.i., and the association between IB LLGP and Ag-ELISA allowed the detection of all animals since 112 days p.e.i. While all animals could be considered healthy by conventional screening tests, the use of immunoassays for detecting $A b$ and $A g$ showed better accuracy; therefore it would be more useful than usual clinical examination for screening cysticercosis in slightly infected pigs.

Key words: swine cysticercosis - larval antigens - antibodies - enzyme-linked immunosorbent assay - immunoblot

Cysticercosis is a frequent infection in pigs and humans of developing countries. The cyst is the larval stage in the tissue of pigs that ingested viable eggs of Taenia solium. When humans ingest raw or undercooked pork meat containing $T$. solium cysts, they develop adult tapeworm in their small intestine (Garcia \& del Bruto 2000, Verastegui et al. 2003). The contact of swine and people with human feces, the lack of pork meat inspection, and the consumption of uncooked or undercooked pork meat are factors promoting and maintaining such disease transmission (Sarti et al. 1988, Garcia et al. 1991, PrestesCarneiro et al. 2006).

The inspection of pork meat for human consumption, showing about $70 \%$ of sensitivity (Phiri et al. 2002, Ngowi et al. 2004), reduces the transmission risk mainly when animals present high degree of infection, which is more likely to occur in clandestinely raised animals. On the other hand, the inspection in low parasite burden animals showed to be less efficient since a detailed post-

Financial support: Fapesp (grant 2002/12061-0 to AJV); Fapesp fellowship to NME (03/10747-4); CNPq fellowship to AHI (107974/2003-7)

+Corresponding author: ajvaz@usp.br

Received 28 February 2007

Accepted 20 June 2007 mortem exam of the meat would cause commercial losses (Gonzalez et al. 1990, Pinto et al. 2000).

Immunoassays for antibody (Ab) detection can be useful on a stage previous then slaughter, identifying the non-infected animals from those probably infected. Several authors have being using enzyme-linked immunosorbent assay (ELISA) and immunoblot (IB) in serum samples from naturally infected animals (Gonzalez et al. 1990, Pathak et al. 1994, Sciutto et al. 1998) and experimentally infected animals (Aluja et al. 1996, Sciutto et al. 1998) with sensitivity and specificity over 70 and $73 \%$, respectively for ELISA, and 90 and $100 \%$, respectively for IB, showing the advantages of the IB assay. Some authors have used the $T$. crassiceps antigen instead of T. solium larvae antigen (Ag), especially when it is hard to obtain cysts of naturally infected pigs (Biondi et al. 1996, Pinto et al. 2000, Nunes et al. 2000).

Several studies have reported good efficiency on Ag research in cerebral spinal fluid (CSF) of patients with neurocysticercosis (Chang-Yuan et al. 1992, Diaz et al. 1992, Garcia et al. 2000, Pardini et al. 2001), but the use of serum samples introduces several circulating components that can interfere in the assay, turning it a less reproducible method. There are reports of lower efficiency on $\mathrm{Ag}$ research in swine serum even in animals with high infection levels. Part of these studies presented confirmed clinical and post-mortem examination infection (Sciutto et al. 1998, Nguekam et al. 2003, RodríguezHidalgo et al. 2003, Sato et al. 2003). 
Our aim is to implement more accurate and efficient methods through immunoassay evaluation for $\mathrm{Ab}$ and $\mathrm{Ag}$ detection in order to improve the screening of swine with low levels of parasite burden.

\section{MATERIAL AND METHODS}

Experimental infection - T. solium was obtained from a patient after niclosamide treatment. The eggs were obtained from gravid proglottids, carefully washed, and stored in physiological saline with antibiotics $(0.85 \%$ sodium chloride containing 1000 units $/ \mathrm{ml}$ penicillin and 100 units $/ \mathrm{ml}$ streptomycin) at $4^{\circ} \mathrm{C}$ during 28 days (Lightowlers et al. 1996). In vitro eggs hatching was performed using sodium hypoclorite as previously described (Laws 1968, Stevenson 1983). Eggs were then rinsed, resuspended in sterile saline solution $(\mathrm{NaCl}$ $0.15 \mathrm{M}$, Merck, Germany) and used to infect the swine.

Seven 2-month-old Landrace swine were orally infected with approximately 200,000 eggs discharged in the mouth of the animals through a pipette. After that, food and water was given to the animals, which were bred in intensive pig farming. Food and water quality was kept under control during the whole experiment to avoid possible contamination. Blood samples of each of the animals were periodically collected during a period of 140 days. Serum samples were separated and stored at $-20^{\circ} \mathrm{C}$. At the end of the experiment, all swine were humanly slaughtered and their whole muscles, brain and visceral organs (heart, lungs, liver, kidneys, and spleen) were cut into thin slices (about $0.5 \mathrm{~cm}$ ) in search of cysts. After that they were counted and classified as vesicular or caseous, depending on their macroscopic appearance.

Control groups - The healthy control group was composed of serum samples from 15 swine without any cysts in tongue inspection, which were raised on a local farm with very good hygienic conditions and without any case of cysticercosis or other parasitic diseases for 20 years. These animals received food and water with quality control.

The positive control group was composed of serum samples from four swine with cysticercosis, confirmed by tongue inspection and usual necropsy, showing a lot of cysts in the post-mortem examination, characterizing them as highly infected animals.

Ag - The vesicular fluid of T. crassiceps (VF-Tcra) was obtained as described by Vaz et al. (1997). The 18/ $14 \mathrm{kDa}$ protein was obtained from VF-Tcra as described by Espindola et al. (2005).

SDS-PAGE and IB - The membranes with $18 / 14 \mathrm{kDa}$ antigen were prepared as described before (Espindola et al. 2005) and then they were blocked by treatment with $5 \%$ skim milk in PBS containing $0.3 \%$ Tween 20 (Merck) for $2 \mathrm{~h}$ and washed in PBS containing 0.3\% Tween 20 (PBS-T). Dr Victor CW Tsang, of the Immunology Department, Division of Parasitic Diseases, Centers for Disease Control and Prevention, US, kindly provided the strips for IB with lentil-lectin-purified glycoproteins (LLGP) of $T$. solium and the reagents for IB.

Both IB, 18/14 and LLGP were performed similarly as described by Tsang et al. (1989), with some modifi- cations. The conjugate $(1: 8000)$ and sample $(1: 50)$ were diluted in PBS-T containing 1\% skim milk (Nestle, Brazil). The presence of any band was considered as positive reaction for 18/14 (18-, $14 \mathrm{kDa})$ and for LLGP (50-, 42-39-, 24-, 21-, 18-, 14-, $13 \mathrm{kDa}$ ).

Ab-ELISA - Flat-bottom polystyrene plates (Costar Corning, US) were coated with $100 \mu \mathrm{l}$ of VF-Tcra (0.05 $\mu \mathrm{g} /$ well) in $0.5 \mathrm{M}$ carbonate-bicarbonate buffer ( $\mathrm{pH} 9.6$ ) for $18 \mathrm{~h}$ at $4^{\circ} \mathrm{C}$. Skim milk (5\%) in PBS solution containing $0.05 \%$ Tween 20 was used as a blockade. The conjugated [1:6,000 (Sigma, US)] and serum samples (1:50) were diluted in PBS-T containing $1 \%$ skim milk. Orthophenylenediamine $(1 \mathrm{mg} / \mathrm{ml})$ and $\mathrm{H}_{2} \mathrm{O}_{2}(1 \mu \mathrm{l} / \mathrm{ml})$ diluted in $0.2 \mathrm{M}$ citrate buffer ( $\mathrm{pH}$ 5.0) were used as chromogen substrate. Incubations were carried out at $37^{\circ} \mathrm{C}$ for $1 \mathrm{~h}$ in all steps except for that with the substrate $(15 \mathrm{~min})$. The reaction was interrupted with $4 \mathrm{~N}$ $\mathrm{H}_{2} \mathrm{SO}_{4}$. The absorbance was obtained at $492 \mathrm{~nm}$ in a plate reader (SLT-Spectra, US). The cut off was chosen using the ROC Curve as described by Kollef and Shuster (1994).

Detection of circulating Ag by sandwich - ELISA (AgELISA) - Serum samples were tested for detecting circulating Ag of T. solium using Ag-ELISA with anti-excretory/ secretory $\mathrm{Ag}$ of in vitro cultures of $T$. crassiceps cysticerci monoclonal Ab (anti-ES MoAb), obtained by Espindola et al. (2002), at concentration of $0.34 \mu \mathrm{g} / \mathrm{ml}$ in PBS $0.02 \mathrm{M}$. The anti-ES MoAb was conjugated with biotin as described before (Harlow \& Lane 1988).

The coated plates were incubated at $37^{\circ} \mathrm{C}$ for $2 \mathrm{~h}$ and more $18 \mathrm{~h}$ at $4{ }^{\circ} \mathrm{C}$, and then the plates were washed with $0.15 \mathrm{M} \mathrm{NaCl}$ containing $0.05 \%$ Tween 20 . A solution of $3 \%$ oxidized bovine serum albumin (Glass et al. 1981) in PBS solution containing $0.05 \%$ Tween 20 was used as blockade. The dilution solution of sample and conjugates was $1 \%$ oxidized bovine serum albumin in PBS solution containing $0.05 \%$ Tween 20 . All incubations were carried out at $37^{\circ} \mathrm{C}$, except for the serum samples, which were diluted $1: 100$, and incubated at $37^{\circ} \mathrm{C}$ for $1 \mathrm{~h}$ and at $4^{\circ} \mathrm{C}$ for $18 \mathrm{~h}$. After washing, biotinylated Anti-ES MoAb at concentration of $0.14 \mathrm{mg} / \mathrm{ml}$ was incubated, and new washes were performed. The second conjugate avidinperoxidase (Sigma) was incubated. After washing procedures, the chromogenic substrate $\left(\mathrm{OPD} / \mathrm{H}_{2} \mathrm{O}_{2}\right)$ was added and the reaction was interrupted with $4 \mathrm{~N} \mathrm{H}_{2} \mathrm{SO}_{4}$ after $15 \mathrm{~min}$. The absorbance was obtained at $492 \mathrm{~nm}$ in a plate reader (SLT-Spectra). The results were expressed in reactivity index (RI), which was the ratio between the absorbance of the tested samples and the blanks of the reactions. The blank was composed of all components of the assay, except the sample itself. The optimum dilution for the conjugates was obtained by titration using positive and healthy control samples. The cut off was chosen using the ROC Curve as described by Kollef and Shuster (1994).

Ethics committee approval - Animal manipulations were approved by the Ethics Committee for Experimental Animals of the FCF-USP (project 13/2003) adopted by the Brazilian Committee for Experimental Animals. 


\section{RESULTS}

Parasite burden - The animals were humanly slaughtered 140 days after the experimental infection, presenting no cysts by manually palpation tongue inspection. When conducting detailed post-mortem exam (not routinely used) it could be verified that the number of metacestodes in muscles varied significantly from one swine to another ( 1 to $85 ; 33.7 \pm 31.3)$. All found cysts showed vesicular aspect. The efficiency of the experimental infection obtained was low, presenting a mean value of $0.17 \%$ o ( 0.01 to $0.42 \%$ ). Three animals presented cysts in tongue by detailed post-mortem examination (Table I), although none was detected by tongue palpation.

Detection by Ab-ELISA and IB - The Ab-ELISA test with VF-Tcra showed sensitivity and specificity of $100 \%$ for the positive and negative control groups, respectively. The detection of Ab through the ELISA test was positive at the end of the experiment (collecting day 140) for five animals (71\%). The 60-cyst animal and the 11-cyst swine did not present $\mathrm{Ab}$ on the slaughter day (Fig. 1).

\section{TABLE I}

Distribution of cysts per organs and areas in experimentally infected pigs, found by post-mortem exam. Each column corresponds to one animal

Organ/Area Number of cysts in experimentally infected pigs

\begin{tabular}{lrrrrrrr}
\hline Heart & 4 & 9 & 4 & 2 & 0 & 1 & 0 \\
Diaphragm & 0 & 4 & 3 & 2 & 0 & 0 & 0 \\
Tongue & 3 & 5 & 0 & 1 & 0 & 0 & 0 \\
Masseter & 7 & 0 & 4 & 1 & 2 & 0 & 0 \\
Cervical area & 2 & 0 & 0 & 0 & 0 & 0 & 0 \\
Esophagus area & 0 & 0 & 1 & 0 & 0 & 0 & 0 \\
Anterior limb & 28 & 13 & 7 & 4 & 3 & 3 & 0 \\
Posterior limb & 32 & 7 & 15 & 8 & 4 & 1 & 1 \\
Dorsal area & 9 & 18 & 12 & 6 & 2 & 0 & 0 \\
Neck area & 0 & 2 & 1 & 2 & 0 & 1 & 0 \\
Maxillary area & 0 & 2 & 0 & 0 & 0 & 0 & 0 \\
\hline Total per animal & 85 & 60 & 47 & 26 & 11 & 6 & 1 \\
\hline
\end{tabular}

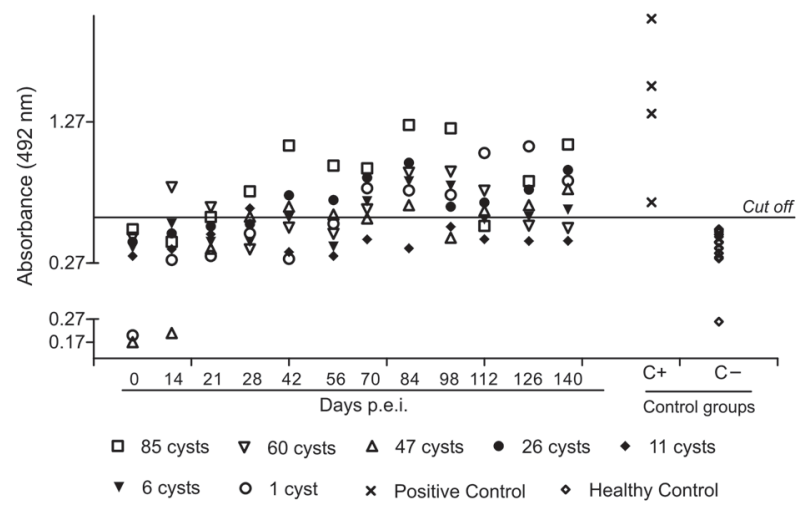

Fig. 1: results expressed in absorbance levels, considering each collecting day (days p.e.i.) using enzyme-linked immunosorbent assay for antibody detection, of serum samples from seven experimentally infected pigs as well as from both the positive $(\mathrm{C}+)$ and the healthy $(\mathrm{C}-)$ control groups. The experimentally infected animals were represented according to the number of cysts found in the post-mortem examination.
The reactivity started with the serum samples collected at 56 days post-experimental infection (days p.e.i.) for both IB (18/14 and LLGP). At 56 days p.e.i., the IB 18/14 was positive for four animals (57\%), showing $1,6,47$, and 60 cysts, while the IB LLGP was positive for two animals (29\%), being one with one and the other with six cysts. The animal with six cysts was positive by IB $18 / 14$ just in collecting day 56 ; however by IB LLGP the positivity was kept until the end.

By IB 18/14, the 26-cyst animal and the 85-cyst swine presented reactivity starting in 70 days p.e.i., with positivity of $71 \%$, corresponding to five animals with $85,26,60,47$, and 1 cyst. The early-recognized band by IB $18 / 14$ was $14 \mathrm{kDa}$.

By IB LLGP, the 85-cyst animal and the 26-cyst swine presented reactivity starting in 70 days p.e.i., with positivity of $57 \%$, corresponding to the serum samples of four animals with $85,26,6$, and 1 cyst. For two other animals (reaching $86 \%$ all together) reactivity became positive after 84 and 112 days of the experimental infection. The early-recognized bands were 50- and $24 \mathrm{kDa}$ $(29 \%)$, although the reactivity standard was really heterogeneous (Table II).

In addition, the swine with 11 cysts showed reactivity in both IB tests only in the 70 days p.e.i. (Table II).

Detection of circulating Ag by sandwich-ELISA (AgELISA) - The Ag-ELISA showed sensitivity and specificity of $100 \%$ (control groups). Serum samples of four animals $(57 \%)$ presented reactivity starting in 112 days p.e.i. The swine with 11 cysts (showing negative reactivity by IB and Ab-ELISA at the end of the infection) and the one with six cysts presented reactivity for antigen in all samples (Fig. 2).

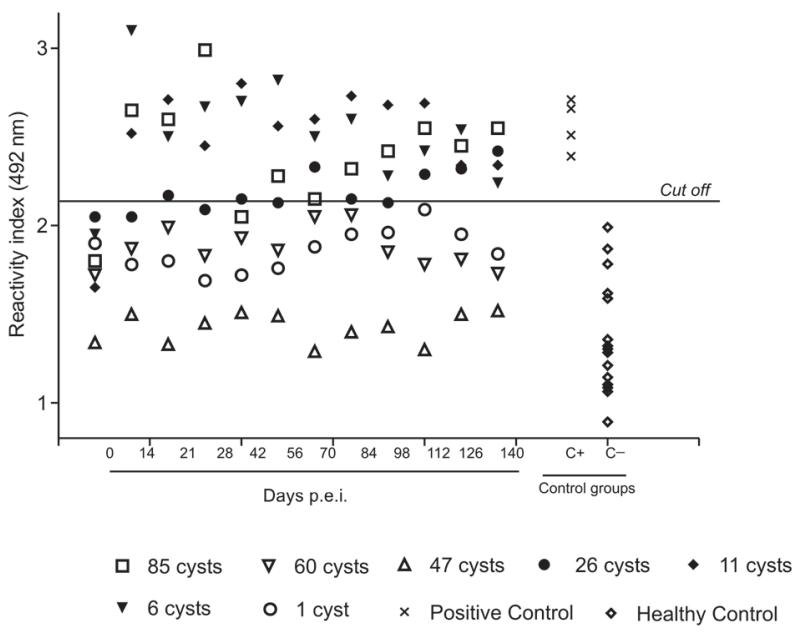

Fig. 2: results expressed in reactivity index, considering each collecting day (days p.e.i.) using sandwich enzyme-linked immunosorbent assay for circulating antigen detection, of serum samples from seven experimentally infected pigs as well as from both the positive $(\mathrm{C}+)$ and the healthy (C-) control groups. The experimentally infected animals were represented according to the number of cysts found in the post-mortem examination. 
TABLE II

Number of serum samples with reactivity according to antigen fraction recognized in immunoblot 18/14 and immunoblot lentil-lectinpurified glycoproteins (LLGP) in each day of sample collection after experimental infection (days p.e.i.).

\begin{tabular}{|c|c|c|c|c|c|c|c|c|c|}
\hline \multirow{2}{*}{$\begin{array}{l}\text { Days } \\
\text { p.e.i. }\end{array}$} & \multicolumn{2}{|c|}{$\begin{array}{l}\text { IB 18/14 (kDa) } \\
\text { Cysts }^{b}\end{array}$} & \multicolumn{7}{|c|}{$\begin{array}{c}\text { IB LLGP (kDa) } \\
\text { Cysts }^{b}\end{array}$} \\
\hline & 18 & 14 & 50 & $39-42$ & 24 & 21 & 18 & 14 & 13 \\
\hline 56 & $\begin{array}{c}2 \\
\left(6^{a}, 1\right)\end{array}$ & $\begin{array}{c}4 \\
\left(60,47,6^{a}, 1\right)\end{array}$ & $\begin{array}{l}1 \\
(6)\end{array}$ & $\begin{array}{c}1 \\
(1)\end{array}$ & 0 & 0 & 0 & 0 & 0 \\
\hline 70 & $\begin{array}{c}4 \\
(85,60,47,1)\end{array}$ & $\begin{array}{c}6 \\
\left(85,60,47,26,11^{a}, 1\right)\end{array}$ & $\begin{array}{c}3 \\
(85,26,6)\end{array}$ & $\begin{array}{c}2 \\
(85,1)\end{array}$ & 2 & 0 & $\begin{array}{c}0 \\
\left(11^{a}\right)\end{array}$ & $\begin{array}{c}1 \\
(26)\end{array}$ & 1 \\
\hline 84 & $\begin{array}{c}5 \\
(85,60,47,26,1)\end{array}$ & $\begin{array}{c}5 \\
(85,60,47,26,1)\end{array}$ & $\begin{array}{c}4 \\
(85,60,26,6)\end{array}$ & $\begin{array}{c}3 \\
(85,60,1)\end{array}$ & $\begin{array}{c}4 \\
(85,60,26,1)\end{array}$ & $\begin{array}{c}1 \\
(1)\end{array}$ & $\begin{array}{c}1 \\
(85)\end{array}$ & 0 & $\begin{array}{c}2 \\
(85,26)\end{array}$ \\
\hline 98 & $\begin{array}{c}5 \\
(85,60,47,26,1)\end{array}$ & $\begin{array}{c}5 \\
(85,60,47,26,1)\end{array}$ & $\begin{array}{c}4 \\
(85,60,26,6)\end{array}$ & $\begin{array}{c}4 \\
(85,60,6,1)\end{array}$ & $\begin{array}{c}4 \\
(85,60,26,1)\end{array}$ & $\begin{array}{c}1 \\
(1)\end{array}$ & $\begin{array}{c}1 \\
(85)\end{array}$ & $\begin{array}{c}1 \\
(1)\end{array}$ & $\begin{array}{c}4 \\
(85,60,47,26)\end{array}$ \\
\hline 112 & $\begin{array}{c}5 \\
(85,60,47,26,1)\end{array}$ & $\begin{array}{c}5 \\
(85,60,47,26,1)\end{array}$ & $\begin{array}{c}5 \\
(85,60,47,26,6)\end{array}$ & $\begin{array}{c}4 \\
(85,60,6,1)\end{array}$ & $\begin{array}{c}5 \\
(85,60,26,6,1)\end{array}$ & $\begin{array}{c}1 \\
(1)\end{array}$ & $\begin{array}{c}1 \\
(85)\end{array}$ & $\begin{array}{c}1 \\
(1)\end{array}$ & $\begin{array}{c}4 \\
(85,60,47,26)\end{array}$ \\
\hline 126 & $\begin{array}{c}5 \\
(85,60,47,26,1)\end{array}$ & $\begin{array}{c}5 \\
(85,60,47,26,1)\end{array}$ & $\begin{array}{c}5 \\
(85,60,47,26,6)\end{array}$ & $\begin{array}{c}4 \\
(85,60,6,1)\end{array}$ & $\begin{array}{c}5 \\
(85,60,26,6,1)\end{array}$ & $\begin{array}{c}2 \\
(26,1)\end{array}$ & $\begin{array}{c}1 \\
(85)\end{array}$ & $\begin{array}{c}2 \\
(26,1)\end{array}$ & $\begin{array}{c}4 \\
(85,60,47,26)\end{array}$ \\
\hline 140 & $\begin{array}{c}4 \\
(85,47,26,1)\end{array}$ & $\begin{array}{c}5 \\
(85,60,47,26,1)\end{array}$ & $\begin{array}{c}5 \\
(85,60,47,26,6)\end{array}$ & $\begin{array}{c}4 \\
(85,60,6,1)\end{array}$ & $\begin{array}{c}6 \\
85,60,47,26,6,1)\end{array}$ & $\begin{array}{c}2 \\
(26,1)\end{array}$ & $\begin{array}{c}1 \\
(85)\end{array}$ & $\begin{array}{c}3 \\
(47,26,1)\end{array}$ & $\begin{array}{c}4 \\
(85,60,47,26)\end{array}$ \\
\hline
\end{tabular}

$a$ : reactivity presented only once at that day p.e.i.; $b$ : number of cysts found in each animal.

\section{TABLE III}

Positivity percentage of serum samples from experimentally infected animals obtained in different collecting days post-experimental infection (days p.e.i.) using an association of methods for antigen researching (Ag-ELISA) and antibodies researching [Ab-ELISA, IB 18/14 and immunoblot lentil-lectin-purified glycoproteins (IB LLGP)]

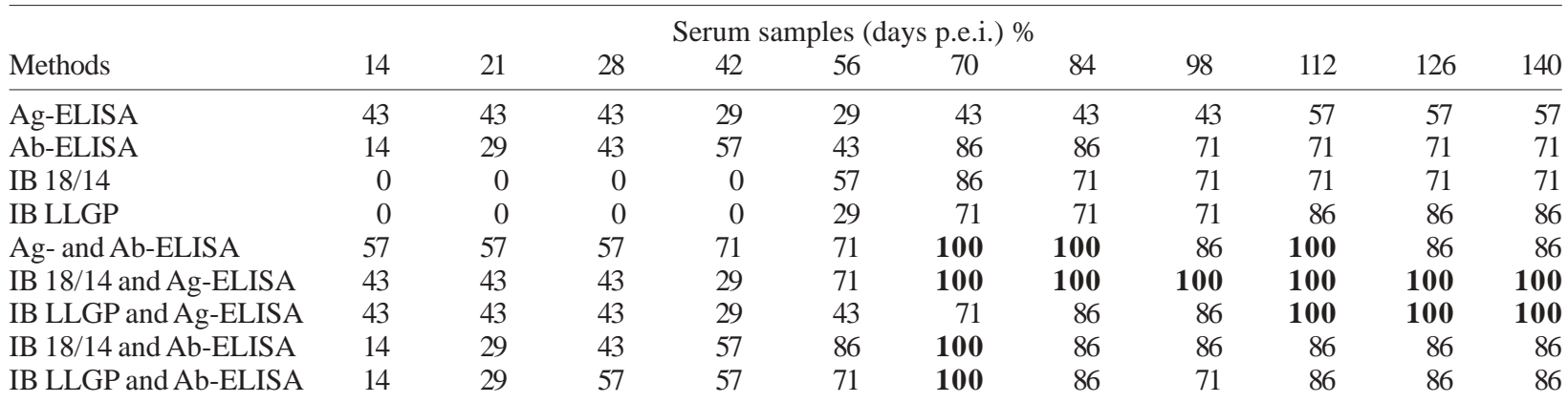

The association between Ag-ELISA with either IB (18/14 or LLGP) allowed the detection of all infected animals at the slaughter day (140 days p.e.i.). The use of IB 18/14 with Ag-ELISA detected all infected animals starting in 70 days p.e.i., while the IB LLGP associated with Ag-ELISA allowed the detection of all animals starting in 112 days p.e.i. (Table III).

\section{DISCUSSION}

Several authors have agreed that swine with low cyst burden may escape from being detected by meat inspections therefore maintaining parasite transmission when slightly infected carcasses would remain in the food chain (Sciutto et al. 1998, Nunes et al. 2000). In our experiment, none of the animals, slaughtered after 140 days of the infection, showed clinical aspects of cysticercosis or cysts by tongue palpation. On the other hand, it is likely that conventional post-mortem exam, a visual inspection by macroscopic examination on different sites of the carcass including heart, diaphragm, masseters, tongue, neck, shoulder, intercostal, and abdominal muscles (Boa et al. 2002), would not detect cysts on experimentally infected animals. In addition, a detailed post-mortem exam showed 1 to 85 cysts from one swine to another (Table I). Other authors have agreed that usual necropsy is not appropriate to identify apparently healthy swine since lesions could be overlooked in animals with low infection levels (Gonzalez et al. 1990). Besides, the best routinely used exam requires several meat-screening cuts, damaging the product for commercial purposes. 
The infection efficiency was very low. We cannot exclude the probability of only few eggs being viable at the moment of the experimental infection. Otherwise, after eggs ingestion, the outer shell of eggs are digested in the pigs stomach, releasing and activating the tiny onchospheres, which penetrate the intestinal blood vessels and reach the general circulation, so if the digestion procedure was not adequate it could result in the no liberation of the larvae from the eggs. On the other hand, in the experimental infection the eggs had to be discharged in the mouth of the animals, risks are that not all the eggs were adequately ingested.

Other authors have obtained infection efficiency varying from 0.28 to $5 \%$ (Molinari et al. 1983, Pathak \& Gaur 1990, Tsang et al. 1991, Nascimento et al. 1995). The ingestion of entire proglottids is the most efficient way of infection (Nguekam et al. 2003). We have to consider that all animals were exposed to an equal number of eggs and some parasites could be destroyed by the immune response of some animals during parasite development stages. The efficiency for establishing the infection may also depend on the viability of the eggs (Santamaria et al. 2002).

The complete development of cysts can take about 60 days after eggs ingestion (Flisser 1991, Carpio 2002). In our study only vesicular cysts were observed at 140 days p.e.i. In agreement with our results, Aluja et al. (1996) found caseous cysts only 200 days after the infection. On the other hand, Santamaria et al. (2002) found the presence of caseous cysts as early as 60 days after the experimental infection.

We used serum samples of healthy control group animals which had lived under good raising conditions and without contacting garbage or feces for the standardization of the immunoassays, reproducing the condition of experimentally infected animals. Thus, the reactivity observed for the experimentally infected group was expected to be only a result of the ingestion of $T$. solium eggs. The performance of immunoassays for detecting antigens and/or antibodies in slightly infected animals is not quite clear. The experimentally infected animals included in this research represent a group of slightly infected animals. In case commercialized animals raised under supervision and with origin control present infection, it is expected to be a slight one.

Although the Ab-ELISA showed $100 \%$ of positivity in the control group (highly infected animals) only five experimentally infected animals $(71 \%)$ showed positive results of $\mathrm{Ab}$ at the end of the experiment (140 days p.e.i.). Sato et al. (2003) obtained better sensitivity, as early as 30 days after the experimental infection, in pigs with 16 or more cysts. The use of glycoproteins and recombinant Ag could justify such efficiency. If Ab-ELISA was used for screening purposes, a 0.4 cut off could be adopted allowing the detection of all infected animals. On the other hand, the specificity of the test would be of only $62 \%$, turning the assay less interesting for screening animals since it would require the use of IB assay for confirming the infection, increasing its costs and screening time (Fig. 1).
By both IB (18/14 and LLGP) the reactivity standard was found to be really heterogeneous (Table II). The positivity rates were 71 and $86 \%$ at the end of the experiment (t140) for IB 18/14 and IB LLGP, respectively. In the IB LLGP the early-recognized bands were 50- and $24 \mathrm{kDa}$. On the other hand, Aluja et al. (1996) described that antigens of 13-, 14-, and $18 \mathrm{kDa}$ were most frequently recognized in early infections and antigens of 50-, 39-42-, and $24 \mathrm{kDa}$ were recognized during later stages of the infection. Additionally, Rodriguez- Hidalgo et al. (2006) found that the $\mathrm{Ag}$ of 50- and 39-42 $\mathrm{kDa}$ were the most recognized bands using serum samples of naturally infected pigs.

The difference of sensitivity observed in Ag-ELISA for the positive control group (100\%) and the experimental infected animals (57\%) was probably resulted from the low infection rate of the second group. We also have to emphasize that this assay showed high specificity $(100 \%)$ in agreement with the other authors (Sciutto et al. 1998, Nguekam et al. 2003).

The results here obtained allowed to identify six infected animals (86\%) by Ab detection (IB LLGP) and the seventh infected animal was detected by Ag-ELISA. The association of these methods enabled to detect all infected animals in 112 days p.e.i. The infection was detected in five animals (71\%) by IB 18/14 and in the other two infected animals by Ag-ELISA. The association of these later mentioned methods enabled an earlier detection of all infected animals (starting in 70 days p.e.i.). It is possible that immunocomplexes were formed by $\mathrm{Ag}-\mathrm{Ab}$ equivalence, or more probably by the excess of $\mathrm{Ag}$, once the 6-cyst animal and 11-cyst animal showed reactivity in all the samples assayed in the Ag-ELISA(Fig. 2). Nguekam et al. (2003) supposed that the strong variation in the circulating antigen level might be a result of cysticerci varying metabolic activity and/or of differences in the permeability of the connective tissue capsule around the cysts, only observed in swine with less than 100 cysts. These data are in accordance with our results and they also suggest further investigations on antigen detection that provides better results helping to screen animals in slaughterhouses.

Conducting Ag detection together with Ab researching methods seems to be adequate especially for groups with negative results in IB. The application of these methods in a larger number of animals, under adequate raising conditions, and the detailed analysis of each positive case could help to better define an algorithm to immunoassays applied in swine cysticercosis screening. It is important to point out that the use of immunoassays for detecting $\mathrm{Ab}$ and/or $\mathrm{Ag}$ showed to be more useful than clinical and/or post-mortem examination for cysticercosis screening in slightly infected swine. The application of these immunoassays for swine cysticercosis screening, either in slaughterhouses or in extensive porcine farming, could improve the controlling procedures concerning the $T$. solium cysticercosis, bringing effective contribution to the eradication of the taeniasis-cysticercosis complex. 


\section{ACKNOWLEDGEMENTS}

To Dr Victor CW Tsang of the Division of Parasitic Diseases, Centers for Disease Control and Prevention (DPD-CDC), for the generous donation of the strips and reagents for IB LLGP, and Dr Kathy Hancock (DPD-CDC) for commenting and reviewing the manuscript. To Dr Paulo Sérgio de Arruda Pinto, Universidade Federal de Viçosa, Brazil, for the donation of serum samples of pigs with cysticercosis.

\section{REFERENCES}

Aluja AS, Villalobos ANM, Plancarte A, Rodarte LE, Hernández M, Sciuto E 1996. Experimental Taenia solium cysticercosis in pigs: characteristics of the infection and antibody response. Vet Parasitol 61: 49-59.

Biondi GF, Mucciolo RG, Nunes CM, Richtzenhain LJ 1996. Immunodiagnosis of swine cysticercosis by indirect ELISA employing a heterologous antigen from Taenia crassiceps metacestodes. Vet Parasitol 64: 261-266.

Boa ME, Kassuku AA, Willingham III AL, Keyyu JD, Phiri IK, Nansen P2002. Distribution and density of cysticerci of Taenia solium by muscle groups and organs in naturally infected local finished pigs in Tanzania. Vet Parasitol 106: 155-164.

Carpio A 2002. Neurocysticercosis: an update. Lancet Infect Dis 2: 751-762.

Chang-Yuan W, Hong-Hua Z, Ling-Yun G 1992. A MoAb-based ELISA for detection circulating antigen in CSF of patients with neurocysticercosis. Hybridoma 11: 825-827.

Diaz JF, Verastegui M, Gilman RH, Tsang VCW, Pilcher JB, Gallo C, Garcia HH, Torres P, Montenegro T, Miranda E, The Cysticercosis Working Group of Peru 1992. Immunodiagnosis of human cysticercosis (Taenia solium): a field comparison an antibody-linked immunoelectrotransfer blot (EITB) assay in Peru. Am J Trop Med Hyg 46: 610-615.

Espindola NM, Vaz AJ, Pardini A X, Fernandes I 2002. Excretory/secretory antigens (ES) from in-vitro cultures of Taenia crassiceps cysticerci, and use of an anti-ES monoclonal antibody for antigen detection in samples of cerebrospinal fluid from patients with neurocysticercosis. Ann Trop Med Parasitol 96: 361-368.

Espindola NM, Iha A I, Fernandes I, Takayanagui O M, Machado LR, Livramento JA, Maia AAM, Peralta JM, Vaz AJ 2005. Cysticercosis immunodiagnosis using 18- and 14- kilodalton proteins from $T$. crassiceps cysticercus antigens obtained by immunoaffinity chromatography. J Clin Microbiol 43: 3178-3184.

Flisser A 1991. Taeniasis-cysticercosis: an introduction. Southeast Asian J Trop Med Public Health 22: 233-235.

Garcia HH, del Bruto OH 2000. Taenia solium cysticercosis. Infect Dis Clin North Am 14: 97-119.

Garcia HH, Martinez M, Gilman R, Herrera G, Tsang VC, Pilcher JB, Diaz F, Verastegui M, Gallo C, Porras M 1991. Diagnosis of cysticercosis in endemic regions. Lancet 338: 549-551.

Garcia HH, Parkhouse RME, Gilman RH, Montenegro T, Bernal T, Martinez SM, Gonzales AE, Tsang VC, Harrison LJS, The Cysticercosis Working Group in Peru. 2000. Serum antigen detection in the diagnosis, treatment and follow-up of neurocysticercosis patients. Trans $R$ Soc Trop Med Hyg 94: 673-676.

Glass WF, Bridggs RC, Hnilica LS 1981. Use of lectins for detection of electrophoretically separated glycoproteins transferred onto nitrocellulose sheets. Anal Biochem 115: 219-224.

Gonzalez AE, Cama V, Gilman RH, Tsang VC, Pilcher JB, Chavera A, Castro M, Montenegro T, Verastegui M, Miranda E 1990. Prevalence and comparison of serologic assays, necropsy, and tongue inspection for the diagnosis of porcine cysticercosis in Peru. Am J Trop Med Hyg 43: 194-199.

Harlow E, Lane D 1988. Antibodies - A Laboratory Manual. Byotinylation Using the Succinimide Ester, Cold Spring Harbor Laboratory, New York, 341 pp.

Kollef MH, Schuster DP 1994. Predicting intensive care unit outcome with scoring systems. Underlying concepts and principles. Crit Care Clin 10: 1-18.

Laws GF 1968. The hatching of Taenia solium eggs. Exp Parasitol 23: 1-10.

Lightowlers MW, Rolfe R, Gauci CG 1996. Taenia saginata: vacination against cysticercosis in cattle with recombinant onchospheres antigens. Exp Parasitol 84: 330-338.

Molinari JL, Meza R, Suárez B, Palacios S, Tato P 1983. Taenia solium: immunity in hogs to the cysticercus. Exp Parasitol 55: 340-357.

Nascimento EJ, Costa O, Guimares MP, Tavares CAP 1995. Effective immune protection of pigs against cysticercosis. Vet Immunol Immunopathol 45: 127-137.

Ngowi HA, Kassuku AA, Maeda GE, Boa ME, Willingham AL 2004. A slaughter slab survey for extra-intestinal porcine helminth infection in northern Tanzania. Trop Anim Health Prod 36: 335-340.

Nguekam A, Zoli AP, Vondou L, Pouedet SMR, Assana E, Dorny P, Brandt J, Losson B, Geerts S 2003. Kinetics of circulating antigens in pigs experimentally infected with Taenia solium eggs. Vet Parasitol 111: 323-332.

Nunes CM, Biondi GF, Heinemann MB, Richtzenhain LJ 2000. Comparative evaluation of an indirect ELISA test for diagnosis of swine cysticercosis employing antigen from Taenia solium and Taenia crassiceps metacestodes. Vet Parasitol 93: $135-140$.

Pardini AX, Vaz AJ, Machado LR, Livramento JA 2001. Cysticercus antigens in cerebrospinal fluid samples from patients with neurocysticercosis. J Clin Microbiol 39: 3368-3372.

Pathak KML, Gaur SNS 1990. Immunization of pigs with culture antigens of Taenia solium. Vet Parasitol 34: 353-356.

Pathak KM, Allan JC, Ersfeld K, Craig PS 1994. A western blot and ELISA assay for the diagnosis of Taenia solium infection in pigs. Vet Parasitol 53: 209-217.

Phiri IK, Dorny P, Gabriel S, Willingham III AL, Speybroeck N, Vercruysse J 2002. The prevalence of porcine cysticercosis in Eastern an Southern provinces of Zambia. Vet Parasitol 108: 31-39.

Pinto PSA, Vaz AJ, Germano PML, Nakamura PM 2000. Performance of the ELISA test for swine cysticercosis using antigens of Taenia solium and Taenia crassiceps cysticerci. Vet Parasitol 88: 127-180.

Prestes-Carneiro LE, Freitas SBZ, Zago SCSZ, Miguel NA, Primo OB, Iha AH, Espíndola NM, Vaz AJ 2006. Taeniosis-cysticercosis complex in individuals of a peasants' settlement (Teodoro Sampaio, Pontal of Paranapanema, SP, Brazil). Mem Inst Oswaldo Cruz 101: 15-20. 
Rodriguez-Hidalgo R, Benítz-Ortiz W, Praet N, Saa LR, Vercruysee J, Brandt J, Dorny P 2006. Taeniasis-cysticercosis in Sourthen Ecuador: assessment of infection status using multiple laboratory diagnostic tools. Mem Inst Oswaldo Cruz 101: 779-782.

Rodriguez-Hidalgo R, Benítz-Ortiz W, Dorny P, Geerts S, Geysen D, Ron-Román J, Proaño-Pérez F, Chávez-Larrea MA, Barrionuervo-Samaniego M, Celi-Frazo M, Vizcaíno-Ordoñez L, Brandt J 2003. Taeniosis-cysticercosis in man and animals in the Sierra of Northern Ecuador. Vet Parasitol 118: 51-60.

Santamaría E, Plancarte A, Aluja A 2002. The experimental infection of pigs with different numbers of Taenia solium eggs: Immune response and efficiency of establishment. J Parasitol 88: 69-71.

Sarti E, Schantz P, Lara R, Gómez H, Flisser A 1988. Taenia solium taeniasis and cysticercosis in a Mexican village. Am J Trop Med Hyg 39: 194-198.

Sato MO, Yamasaki H, Sako Y, Nakao M, Nakaya K, Plancarte A, Kassuku AA, Dorny P, Geerts S, Benitez-Ortiz W, Hashiguchi Y, Ito A 2003. Evaluation of tongue inspection and serology for diagnosis of Taenia solium cysticercosis in swine: usefulness of ELISA using purified glycoproteins and recombinant antigen. Vet Parasitol 111: 309-322.

Sciutto E, Martinez JJ, Villalobos NM, Hernandez M, Hose MV, Beltran C, Rodarte F, Flores I, Bobadilla JR, Fragoso G, Park- house ME, Harrison LJ, de Aluja AS 1998. Limitations of current diagnostic procedures for the diagnosis of Taenia solium cysticercosis in rural pigs. Vet Parasitol 79: 299-313.

Stevenson P 1983. Observations on the hatching and activation of fresh Taenia saginata eggs. Ann Trop Med Parasitol 77: 399-404.

Tsang VCW, Brand JA, Boyer AE 1989. An enzyme-linked immunoelectrotransfer blot assay and glycoprotein antigens for diagnosing human cysticercosis (Taenia solium). J Infect Dis 159: 50-59.

Tsang VC, Pilcher AJ, Zhow W, Boyer EA, Kamangoman IPE 1991. Efficacy of the immunoblot assay for cysticercosis in pigs and modulated expression of distinct IgM/IgG activities to Taenia solium antigens in experimental infections. Vet Immunol Immunopathol 29: 69-78.

Vaz AJ, Nunes CM, Piazza RMF, Livramento JA, Silva MV, Nakamura PM, Ferreira AW 1997. Immunoblot with cerebrospinal fluid from patients with neurocysticercosis using antigen from cysticerci of Taenia solium and Taenia crassiceps. Am J Trop Med Hyg 57: 354-357.

Verastegui M, Gilman RH, Garcia HH, Gonzalez AE, Arana Y, Jeri C, Tuero I, Gavidia CM, Levine M, Tsang VCW, The Cysticercosis Working Group in Peru 2003. Prevalence of antibodies to unique Taenia solium onchosphere antigens in taeniasis and human and porcine cysticercosis. Am J Trop Med Hyg 69: 438-444. 
